\title{
Kalıp Tasarımının Isıl Şekillendirilmiş Ambalajın Kalınık Dağılımı Üzerine Etkisi
}

\author{
The Effect of Plug Design on Thickness Distribution of Thermoformed Package
}

\author{
Olcay EKȘiं*a , Neslihan YAVUZ ${ }^{\mathrm{b}}$ \\ Kırklareli Üniversitesi, Mühendislik Fakültesi, Makine Mühendisliği Bölümü, 39100, Kırklareli
}

• Geliş tarihi / Received: 25.02.2020 • Düzeltilerek geliş tarihi / Received in revised form: $21.04 .2020 \quad$ • Kabul tarihi / Accepted: 06.05.2020

$\ddot{O} \mathbf{z}$

Isıl şekillendirme prosesi gerek otomotiv gerekse ambalaj sanayiinde en çok kullanılan proseslerden biridir. Bu çalışmada, Polivinil klorür (PVC) filmlerin, erkek kalıpla ısıl şekillendirme sonrası kalınlık dağılımları belirlenmiştir. Erkek kalıbın çapı ve erkek kalıbın dişi kalıp içerisindeki dalma derinliği artırılarak bir dizi ısıl şekillendirme işlemi yapılmış ve numuneler elde edilmiştir. Bu numunelerdeki kalınlık dağılımı karşılaştırmalı olarak grafik yöntemle incelenmiştir. Erkek kalıp çapının ve erkek kalıbın dişi kalıp içerisindeki dalma derinliğinin artırılmasının ısıl şekillendirilen yarı mamullerde özellikle yan duvar ve taban kalınlık dağılımını değiştirdiği tespit edilmiş̧ir.

Anahtar kelimeler: Isıl Şekillendirme, Kalınlık Dağılımı, Kalıp Tasarımı

\begin{abstract}
Thermoforming process is one of the most used processes in both automotive and packaging industry. In this study, thickness distributions of Polyvinyl chloride (PVC) sheets were determined after plug assisted thermoforming. By increasing the diameter of the plug and the plug depth inside the female mould, a series of thermoforming operation were performed and plug assisted thermoformed samples were obtained. Thickness distribution in thermoformed samples was examined comparatively using graphical method. It has been found that increasing the diameter of plug and the plug depth, changes thickness distribution particularly in the side wall and bottom of thermoformed semi-finished samples.
\end{abstract}

Keywords: Thermoforming, Thickness Distribution, Plug Design

\footnotetext{
*a Olcay EKŞİ; olcayeksi@klu.edu.tr, Tel: (0544) 29338 43, orcid.org/0000-0002-2433-6700

b orcid.org/0000-0002-5232-6489
} 


\section{Giriş}

Isıl şekillendirme dünya çapında farklı endüstriyel ürünlerin elde edilmesinde kullanılan bir üretim yöntemidir. Bu proses elektrik-elektronik, sağlık, inşaat, ambalajlama ve otomotiv başta olmak üzere birçok sektörde yaygın olarak kullanılmaktadır. Özellikle termoplastik levha yâda film malzemelerin geniş yüzey alanlı yarı mamullere dönüştürülmesinde çevrim zamanı ve maliyet açısından oldukça verimlidir. Rakip üretim yöntemlerinden, enjeksiyon kalıplama, plastik ekstrüzyon ve ekstrüzyon şişirme kalıplama yöntemlerine nazaran makine ve kalıp maliyetleri dikkate alındığında avantajlı bir prosestir (Penix, 1991; Throne, 1996; Crawford, 1998; Rosato vd., 2001;) Bunun yanında 1sıl şekillendirme yöntemiyle elde edilen ürünlerin kalınlık dağılımlarının her noktasında aynı olmaması ve ürün kalıptan alındıktan sonra istenmeyen kısımların kesilerek atılması gibi ek işlemler bu yöntemin zayıf yönleridir. Kalınlık dağılımının 1sıl şekillendirilmiş ürünlerde her noktada farklı olması ürünün dayanımını etkiler. Eğer 1sıl şekillendirilmiş ürün bir gida ambalajı ise, farklı kalınlık değerleri, farklı gaz ve oksijen geçirgenliği anlamına geleceği için ambalajlanan gıdanın raf ömrünü değiştirir. Dolayısıyla 1sıl şekillendirilmiş ürünün kalitesi söz konusu olduğunda kalınlık dağılımının mümkün olduğu kadar ilk levha yâda film kalınlığına yakın olması bir gerekliliktir (Rosato ve Rosato, 2004; Barry vd., 2006; Pribble, 2013; Schwarzman ve Illig, 2018). Is1l şekillendirme yönteminde termoplastik hammadde etkin sızdırmazlığın sağlanması için öncelikle tutucu çerçeve tarafindan sabitlenir. Sabitlenen hammadde farkli isitma teknikleriyle (firında 1sitma, radyant 1sitıcilar ile 1sitma, kızılötesi isıtma vb.) 1sitılabilir. Hammaddenin türüne göre uygun şekil verme sıcaklığına ulaşan ve tutucu çerçeve tarafindan sabitlenen levha yâda film malzeme, dişi kalıp üzerine yerleştirilir. Vakum, pozitif hava basınc1 ve/veya erkek kalıp kullanılarak tercihen bir ön gerdirme sonrası hammadde şekillendirilir. Soğuyarak katılaştıktan sonra kalıptan alınan yarı mamul istenmeyen kısımların kesilip atıldı kesme kalıbı kullanılarak son şeklini alır. Erkek kalıp kullanmayarak sadece vakum etkisinde isil şekillendirme yapılabilir. Bu durumda yöntem vakumla 1sıl şekillendirme adını alır. Literatürde vakum ve ısı ile şekil verme yöntemi ile ilgili çeşitli araştırmalar bulunmaktadır. O'Connor vd. (2013), 1sıl şekillendirmeyi etkileyen parametrelerin daha iyi anlaşılması için yüksek sıcaklıkta iki eksenli deney verilerine dayanan, Polipropilen için termal davranışı da içine alan bir malzeme modeli öngörerek sonlu elemanlar yöntemini kullanmış, erkek kalıp kullanarak isıl şekillendirme yönteminin simülasyonu üzerine çalışmıştır. Çalışmaların sonucunda, gerçekleş-tirilen modellemenin iki eksenli deneysel verilere iyi bir şekilde uyum sağladığ 1 gözlenmiş ve modellenmenin doğruluğu, deneysel sonuçlar ile karşılaştırılarak belirlenmiştir. Bu çalışmada erkek kalıp ile hammadde arasındaki sürtünmenin en etkili parametrelerden biri olduğu gözlenmiştir. Bunun yanı sira 1si transfer parametrelerinin de etkili olduğu belirlenmiştir. Hosseini vd. (2006), polimer içinde elastik deformasyonların heterojen bir şekilde birikmesi sonucu soğumanın ve gerilme gevşemesinin farklı hızlarda gerçekleştiğini gözlemlemiştir. Bunun bir sonucu olarak test edilen üründe çarpılmalar meydana gelmiştir. Çarpılmaları en az seviyeye indirmek ya da mümkün olduğu durumlarda tamamen gidermek için elastik deformasyonların en az miktarda olması gerekmektedir. Bunu sağlamak için iki aşamadan oluşan kalıp tasarlanmış ve kullanılmıştır. Morales vd. (2014), 1sıl şekillendirilmiş bir parçanın, farklı üretim parametrelerinin değişiminden nasıl etkilendiğini araştırmıştır. Levha sicaklığı, erkek kalıp malzemesi, erkek kalıp sıcaklığı, yüzey kalitesi, erkek kalıbın geometrisi ve hava basıncı değeri incelenen parametreler olarak belirlenmiştir. Erkek kalıbın malzemesinin değiştirilmesi sonucu; levha, erkek kalıba yapışabilmektedir. Bu durum, kalınlık dağılımını belirlemede sürtünmeye göre daha fazla rol oynamaktadır. Chen vd. (2008), 0.125 ve 0.2 mm kalınlıklardaki Polikarbonat (PC) filmlere 1sıl şekillendirme yöntemiyle şekil vermiştir. Isıl şekillendirme gerçekleştirilirken, dişi kalıp sıcaklığı, erkek kalıp dalma derinliği, erkek kalıbın hızı, film malzemenin sicaklığı ve erkek kalıbın bekleme süresi etkin parametreler olarak seçilmiş ve bunların kalınlık dağılımına etkileri incelenmiştir. Isıl şekillendirme ile oluşturulan yarımamullerin yan duvar kalınlıklarındaki değişimin artan dişi kalıp sıcaklı̆̆ı, film malzeme sıcaklığ 1 , erkek kalıp dalma derinliği ve erkek kalıp bekleme süresiyle arttığı, artan erkek kalıp hızıyla azaldığ1 belirlenmiştir. Moustafa vd. (2015), taşıyıcı cepli bant üretimini 1 sıl şekillendirme ile denemiştir. Kalıp malzemesinin termal iletkenliğinin, 1sıl şekillendirilmiş ürünün duvar kalınlık dağılımına etkisini incelemek amacıyla dört farklı kalıp takım malzemesi kullanılmıştır. Kalıp malzemesinin termal iletkenliğinin yüksek olması ve şekillendirme sıcaklığının sabit tutulması daha düzgün kalınlık dağılımına sahip taşıyıcı bant üretmeyi sağladığı aktarılmıştır. Wang ve Nied (1999), 1s1l şekillendirme yönteminde polimer levhanın 1sitılması sonrasında sıcaklık kontrolü yaparak dağılımı optimize etmiş ve 1 sıl 
şekillendirilmiş üründe daha iyi kalınlık dağılımı sağladığını gözlemlemiştir.

Ulusal literatürde erkek kalıp kullanarak 1s1l şekillendirme ile ilgili oldukça sınırlı kaynak bulunmaktadır. Mevcut çalışmalarında daha ziyade 1s1l şekillendirilen ürün ve toplam kalitesini etkileyen parametreler hakkında olduğu bilinmektedir. Buna ek olarak, seri imalat ile üretim yapan birçok ambalaj firmasında kullanılan erkek kalıp malzemesi, çoğunlukla 1sıl iletkenliği oldukça düşük termoplastik, termoset ya da belirli oranlarda karışımlarından oluşmaktadır. $\mathrm{Bu}$ çalışmada ise, 1sıl iletkenliği yüksek olan C1040 çelik malzeme seçilmiştir. Özellikle gida ambalajlama makinelerinde kullanılan erkek kalıpların boyutları hemen hemen dişi kalıp boyutlarındadır. Erkek kalıp ve polimer levha-film, şekil verme esnasında dişi kalıbın iç yüzeyine ya temas eder ya da temas edecek kadar yakındır. Yine sektördeki çoğu ambalajlama makinesi pozitif hava basıncı kullanarak erkek kalıp ile 1sıl şekillendirme yapmaktadır. Bu işlemlerde basınç 1 barın üzerine çıkabilmektedir. Mevcut çalışmada ise erkek kalıbın malzemesi, çap1 ve dişi kalıp içerisindeki dalma derinliği değiştirilerek ürün kalınlık dağılımı üzerindeki etkisi araştırılmıştır. Buna ek olarak şekil verme işlemi vakum kullanılarak gerçekleştirilmiş ve en yüksek basınç değeri 1 bar basıncın altında kalmıştır.

$\mathrm{Bu}$ çalışmada, PETKIMM Petvinil S 23/59 renksiz şeffaf PVC film malzeme kullanılmıştır. $0.5 \mathrm{~mm}$ kalınlığa sahip PVC kullanılarak ilkin erkek kalıp kullanılmadan sadece vakum altında dişi kalıpla 1sıl şekillendirme yapılmıştır. Ardından kalınlık dağılımı belirlenmiştir. Erkek kalıbın dişi kalıp içerisinde dalma derinliği için $35 \mathrm{~mm}$ seçilerek, 30 , $35,40,45$ ve $50 \mathrm{~mm}$ çaplı erkek kalıplar ile 1 sıl şekillendirme ile numuneler elde edilmiştir. $\mathrm{Bu}$ numunelerin kalınlık dağılımları grafik yöntemle belirlenmiş̧ir. Erkek kalıp çap $40 \mathrm{~mm}$ seçilerek dalma derinliği $25,30,35,40$ ve $45 \mathrm{~mm}$ olarak seçilmiş ve isıl şekillendirme ile numuneler elde edilmiştir. Numunelere ait kalınlık dağglımı yine grafik yöntemle belirlenmiştir. Erkek kalıp çapının ve erkek kalıbın dişi kalıp içerisindeki dalma derinliğinin artırılmasının ısıl şekillendirilen yarı mamullerde özellikle yan duvar ve taban kalınlık dağılımını değiştirdiği tespit edilmiştir.

\section{Malzeme ve Yöntem}

Çalışmada $0.5 \mathrm{~mm}$ kalınlığında şeffaf süspansiyon PVC (yoğunluk:0.56-0.62 $\mathrm{gr} / \mathrm{cm}^{3}$ ) film kullanılmıştır. Isıl şekillendirme, OYSAN Makine A.Ş tarafindan üretilen laboratuvar tipi şekil verme ünitesinde gerçekleştirilmiştir. $0.5 \mathrm{~mm}$ kalınlığa sahip PVC film malzeme şekillendirme öncesinde $150 \times 150 \mathrm{~mm}$ boyutlarında kesilerek hazırlanmıştır. Isı1 şekillendirme ünitesi Şekil 1'de gösterilmektedir. Isıl şekillendirme ünitesi kompresör, vakum pompası, pnömatik regülatör ve pistonlar, 1sıtıcılar, taşıyıcı kolonlar ve elektrik sisteminden oluşmaktadır. Isıtıcılar hareketli tipte olmakla beraber $25 \times 25 \mathrm{~cm}^{2}$ isitma alanina sahiptir. 3 adet konkav seramik rezistans 1siticiları teşkil etmektedir. Isıtıcı sıcaklığı $500 \mathrm{C}^{\circ}$,ye kadar çıkabilmektedir.

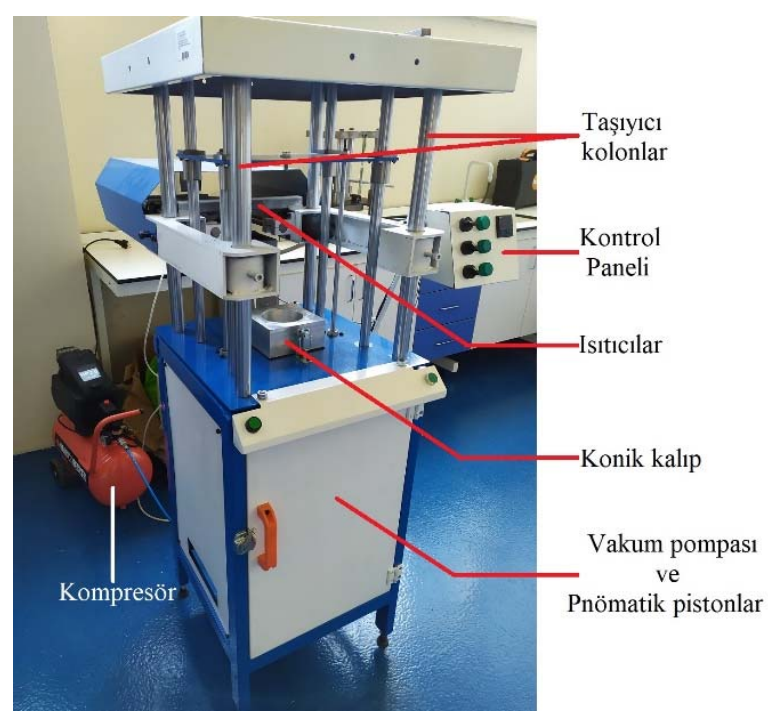

Şekil 1. Laboratuvar tipi ısıl şekillendirme ünitesi

Film malzeme ilk olarak dişi kalıp üst yüzeyine yerleştirilir. Sonra tutucu çerçeve ile kalıp üst yüzeyine bastırılarak sıkıştırılır. Isıtıcılar çekilerek PVC film malzemenin 1sitılması için uygun konuma getirilir. $250 \mathrm{C}^{0}$ sicaklığa sahip isitıcilar belirlenen süre boyunca PVC film malzemeyi belirlenen sıcaklığa kadar isitır. Isitıcilar eski konumuna itilir. Pnömatik tahrik ile erkek kalıp aşağı yönde belirlenen derinlikte hareket eder ve ön gerdirme işlemi tamamlanmış olur. Erkek kalıp film ile hala temasta iken vakum pompas1 çalıştırılarak, filmin dişi kalıbın şeklini alması sağlanır. Erkek kalıp yukarı yönlü hareket ederek eski konumuna geri döner. Vakum, numune şekillendikten 5 saniye sonra kesilir. Bu bekleme, numunenin vakum altında soğuyarak katılaşmasını sağlar ve çarpılmayı azaltmak içindir. Isıl şekillendirme öncesinde tutucu, film malzeme ve kalıp montajı Şekil 2'de gösterilmektedir.

Deneysel çalışmada konik geometrili 2024 serisi alüminyum dişi kalıp kullanılmıştır. Erkek kalıp malzemesi olarak C1040 çeliği seçilmiştir. 


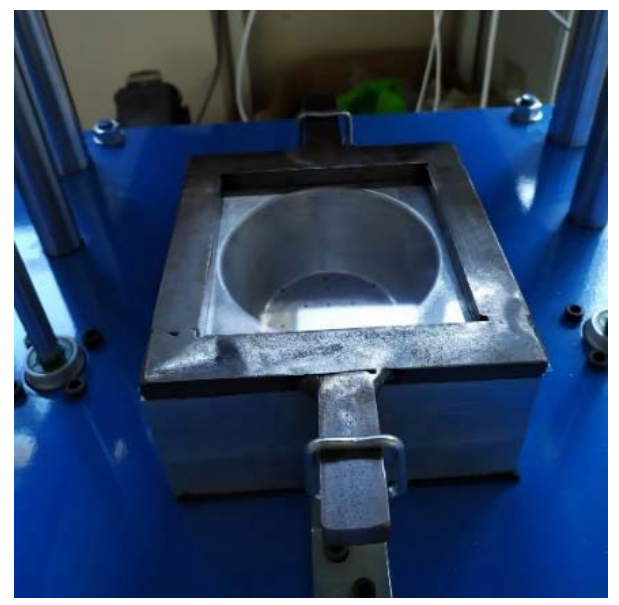

Şekil 2. Tutucu, PVC film ve konik dişi kalıp

Çalışmada kullanılan erkek kalıbın farklı çaptaki dairesel başlıkları ve derinlik ayarı için kullanılan burçlar, Şekil 3'te montajı ise Şekil 4'te verilmiştir.

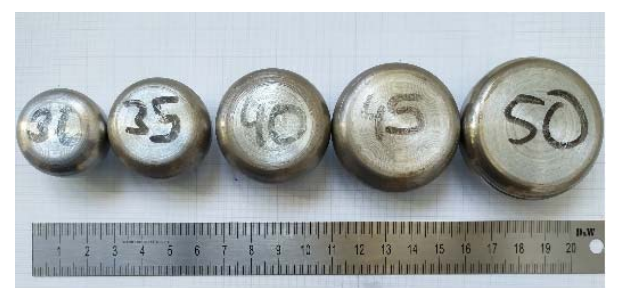

(a)

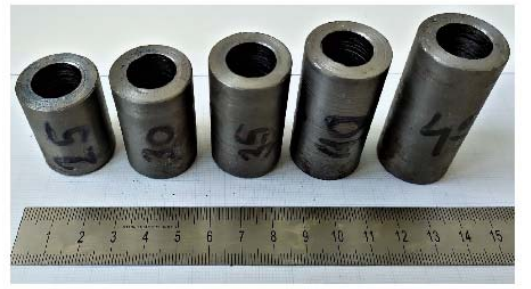

(b)

Şekil 3. (a) Erkek kalıbın farklı çaptaki dairesel zımbaları [mm], (b) Erkek kalıbın dalma derinliğini ayarlayan farklı yükseklikteki burçlar [mm]

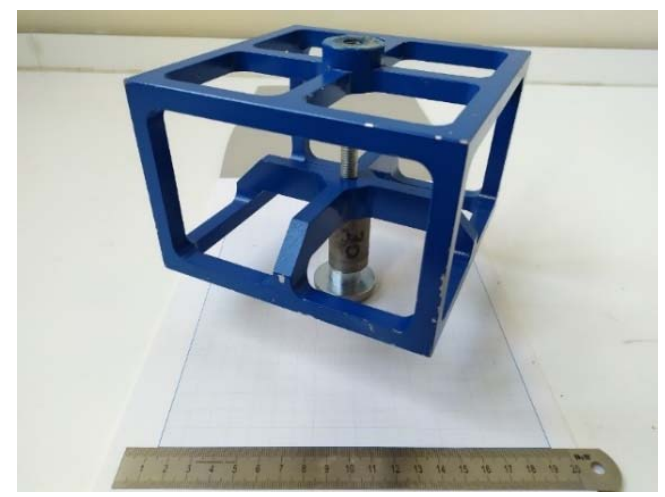

Şekil 4. Erkek kalıp montaj1

Çalışmada kullanılan dişi ısıl şekillendirme kalıbı alüminyumdan Talaşlı şekil verme yöntemiyle belirli bir kritere göre tasarlanarak üretilmiştir.
Kalıp boşluğunun yan duvarlarının draft açısı $15^{0}$ olarak tasarlanmıştır. İç çap değeri $100 \mathrm{~mm}$, derinlik ise $50 \mathrm{~mm}$ olarak belirlenmiştir. Isıl şekillendirme prosesinde üç farklı kritere göre ürün tasarımı, yani kalıp tasarımı yapılabilir. Bunlardan ilki alansal çekme oranı (Areal draw ratio), diğeri doğrusal ya da çizgisel çekme oranı (Linear draw ratio) ve sonuncusu ise 1sıl şekillendirilen ürünün birbirine dik dış boyutlarının oranı olan (h:d) oranıdır (Throne, 1996). Bu kriterler bir ürünün pratik olarak ısıl şekillendirilebilir olup olmadığını ortaya koyabilmek için çıkarılmış eşitliklerdir. Erkek kalıbın kullanılması ve kullanılmaması durumunda bu eşitlikler farklı uygulanır. Ancak çalışmada kullanılan kalıbın kavite yüksekliğinin çapına oranı 1:2 olarak özel bir oran seçilmiş ve bu oranda üretilmiştir. $1 / 2$ oranı sınır bir değerdir. $\mathrm{Bu}$ oran küçüldüğünde, ürün sı̆̆ (shallow) olarak isimlendirilir. Keza bu oran büyüdüğünde ürün derin (deep) olarak nitelendirilir. Isıl şekillendirme prosesinin ismini de çoğu durumda bu oran belirler. Dişi kalıbın taban çapı yaklaşık olarak 73 mm'dir. Erkek kalıp çapının ise en büyük değeri $50 \mathrm{~mm}$ olarak seçilmiştir. Hedef, erkek kalıp ile dişi kalıp arasında en az $10 \mathrm{~mm}$ boşluk kalmasını sağlayabilmektir. Bu yüzden erkek kalıbın en büyük çap değeri $50 \mathrm{~mm}$ seçilerek 5'er mm'lik düşüş ile $45,40,35$, ve $30 \mathrm{~mm}$ seçilmiştir.

Endüstriyel kullanımda 1sıl iletkenliği ve sürtünme katsayısı oldukça düşük polimer bazlı erkek kalıp malzemeleri kullanılmaktadır. Bu çalışmada ise, C1040 gibi 1s1l iletkenliği oldukça yüksek ve üniversal tezgâhlar ile kolayca işlenebilecek erkek kalıpların üretilmesi amaçlanmıştır. Derinlik seçiminde ise $0-50 \mathrm{~mm}$ aralığ 1 belirlenmiştir. Isitılan PVC filmin, erkek kalıp temas etmeden önce yer çekimi etkisiyle, neredeyse 10-15 mm sarktığ 1 tespit edilmiştir. Erkek kalıbın PVC filme etkin temasını sağlamak açısından dişi kalıbın üst yüzeyinden başlayarak $25,30,35,40,45 \mathrm{~mm}$ derinlik değerleri seçilmiştir. Çapın değişiminin etkisini incelemek için derinlik değeri sabit ve 5 farklı derinlik değerinden ortalama bir değer olan $35 \mathrm{~mm}$, dalma derinliğinin etkisini incelemek için ise, yine 5 farklı çap değerinden ortalama değer olan $40 \mathrm{~mm}$ değeri seçilmiştir.

Isıl şekillendirilmiş ürünün kalınlık dağılımını etkileyen en önemli unsurlardan biri de sicaklık dağılımıdır. Isitıcı sıcaklığı PVC filmin degradasyonunu engellemek amaciyla $250 \mathrm{C}^{0}$, de sınırlandırılmıştır. Isıtma süresi ise seçilen erkek kalıp çapı ve dalma derinliği için başarılı bir 1sıl şekillendirme operasyonu sonrasinda her durum için ayrı belirlenmiştir. Isıtma işlemi sonrasında PVC film üzerinde oluşan sicaklık dağılımı 
TESTO 871 Termal kamera kullanılarak belirlenmiştir. Özellikle erkek kalıpla şekil verme işlemlerinde isıtma süreleri tespit edilmiş ve şekil vermenin hemen öncesinde termal görüntüler kaydedilerek ortalama sıcaklık belirlenmiştir. Artan erkek kalıp çapı 1sıtma sürelerini artırmakta keza artan dalma derinliği de 1sitma sürelerini artırmaktadır. Artan 1sıtma süreleri 1s1l şekillendirme sıcaklıklarını da artırmaktadır. Elde edilen 1sıl şekillendirilmiş konik PVC numunelerin dörtte biri kesip alınarak, bu çeyrek numune üzerinde kalınlık ölçümleri yapılmıştır. Kalınlık dağılımın belirlenebilmesi için seçilen her 1 sıl şekillendirme parametresi için 3 adet numune üretilmiş ve ortalama kalınlık değerleri alınmıştır. Numunenin tabanının merkezinden başlayarak toplam 28 farklı noktada, LYK 5318 Kalınlık komparatörü (hassasiyet:0.001mm) kullanılarak kalınlık dağılımı belirlenmiştir. Kalınlık ölçme cihazının ve 1 sıl şekillendirilmiş numunelerin boyutları dikkate alınarak, 28 farklı nokta belirlenmiş ve kalınlık ölçümü yapılmıştır. Isıl şekillendirilmiş PVC konik numune Şekil 5'te verilmiştir. Ek olarak, 1sıl şekillendirme işleminin parametreleri Tablo 1'de verilmektedir.

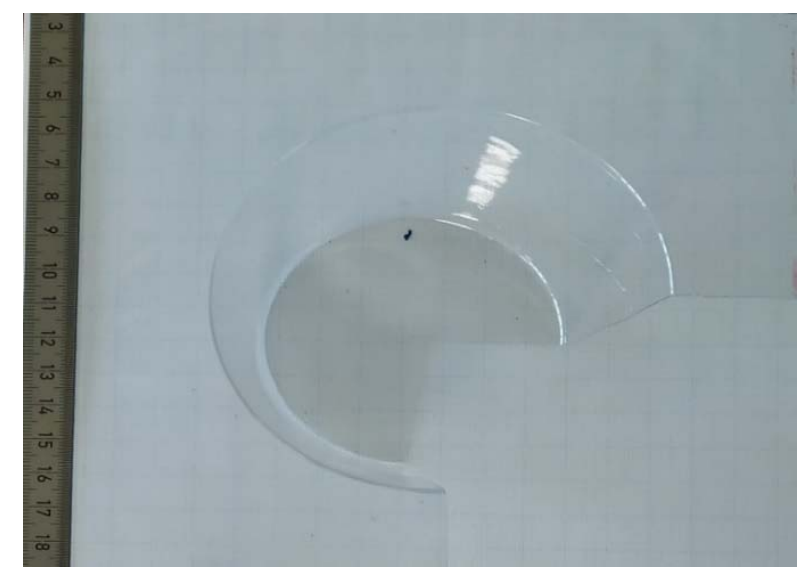

Şekil 5. Isıl şekillendirilmiş ve kalınlık ölçümü yapılmış PVC numune

Tablo 1. PVC film malzemeye ait 1sıl şekillendirme parametreleri

\begin{tabular}{|c|c|c|c|c|}
\hline $\begin{array}{c}\text { Çap } \\
\text { değeri } \\
(\mathrm{mm}) \\
\end{array}$ & $\begin{array}{c}\text { Dalma } \\
\text { derinliği } \\
(\mathrm{mm})\end{array}$ & $\begin{array}{c}\text { Isıtma } \\
\text { süresi } \\
(s)\end{array}$ & $\begin{array}{c}\text { Vakum } \\
\text { değeri } \\
(m m . h g)\end{array}$ & $\begin{array}{c}\text { Isıtıcı } \\
\text { sıcaklığı } \\
\left(C^{0}\right)\end{array}$ \\
\hline \multicolumn{5}{|c|}{ Dişi kalıpla ısıl şekillendirme } \\
\hline- & - & 30 & $640-660$ & 250 \\
\hline \multicolumn{5}{|c|}{ Sabit dalma derinliği(35 mm) ile ısıl şekillendirme } \\
\hline 30 & 35 & 60 & $640-660$ & 250 \\
\hline 35 & 35 & 75 & $640-660$ & 250 \\
\hline 40 & 35 & 90 & $640-660$ & 250 \\
\hline 45 & 35 & 105 & $640-660$ & 250 \\
\hline 50 & 35 & 120 & $640-660$ & 250 \\
\hline \multicolumn{5}{|c|}{ Sabit çap(40 mm) ile ısıl şekillendirme } \\
\hline 40 & 25 & 90 & $640-660$ & 250 \\
\hline 40 & 30 & 105 & $640-660$ & 250 \\
\hline 40 & 35 & 105 & $640-660$ & 250 \\
\hline 40 & 40 & 120 & $640-660$ & 250 \\
\hline 40 & 45 & 120 & $640-660$ & 250 \\
\hline
\end{tabular}

\section{Bulgular}

Isıtılmış film üzerindeki sıcaklık dağılımı 1 sıl şekillendirilmiş numunenin kalınlık dağglımı üzerinde ciddi rol oynamaktadır. Bu yüzden her 1sıtma süresine karş1l1k gelen termal görüntü TESTO firmasına ait bir yazılım ile analiz edilerek ortalama 1sıl şekillendirme sıcaklığı belirlenmiştir. Ortalama Isıl şekil verme sıcaklıkları Şekil 7, Şekil 8, Şekil 9, Şekil 10, Şekil 11, Şekil 12, Şekil 13 ve Şekil 14'te gösterilmiştir. Şekil 6'da ise $250 \mathrm{C}^{0}$ sicaklıktaki 1sitıcılar üzerinde tespit edilen farklı sıcaklık değerleri gösterilmiştir. 


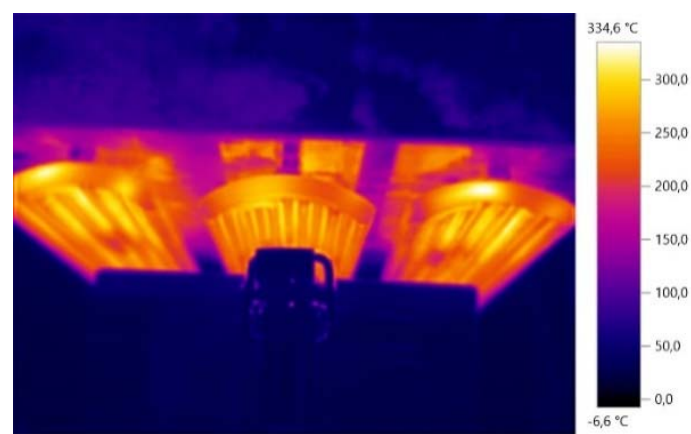

Şekil 6. $250 \mathrm{C}^{\circ}$ sıcaklıktaki isıtıcılar üzerindeki sıcaklık dağılımı
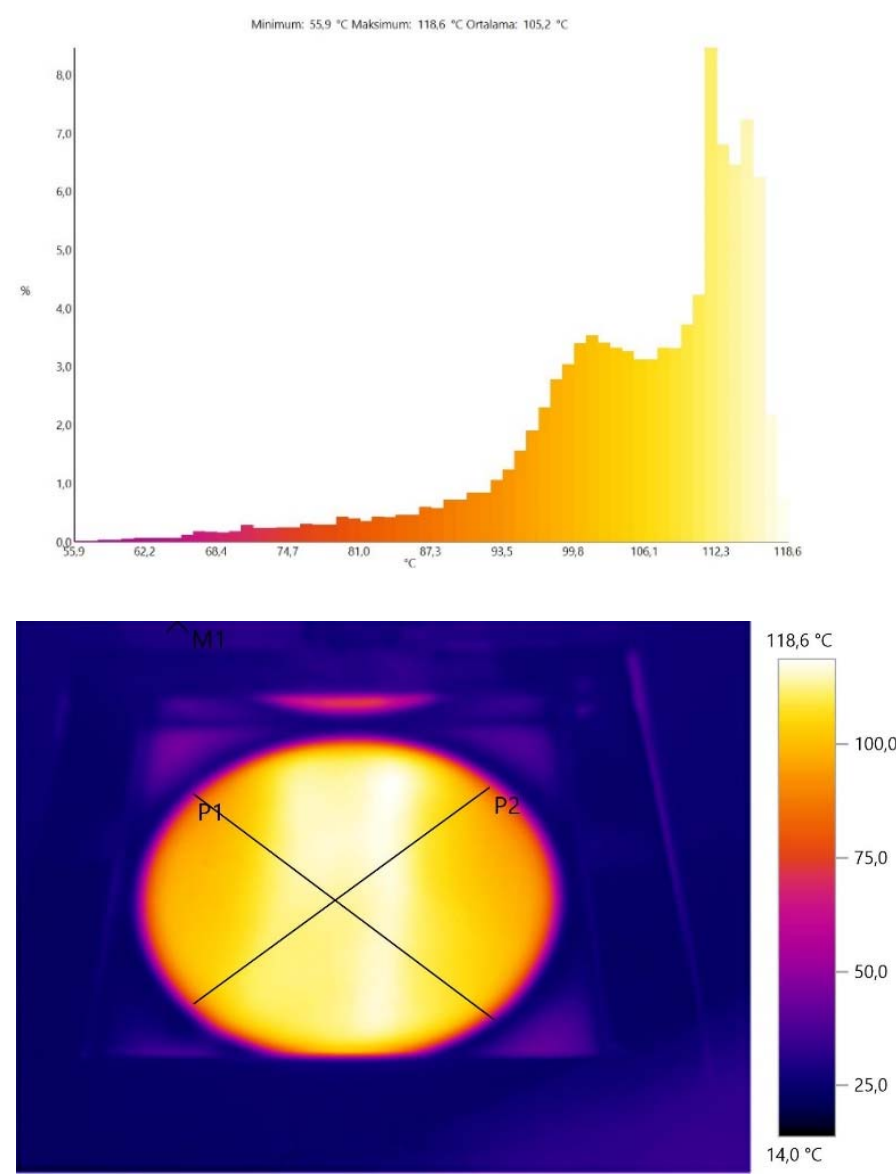

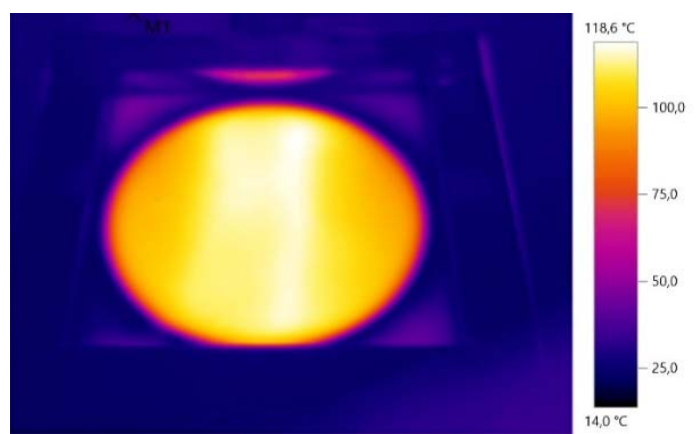

Şekil 7. 30 saniye 1sitma süresinde PVC film üzerindeki sıcaklık dağılımı

4 Şekil 8. 30 saniye isıtma süresinde PVC'nin ortalama 1sıl şekillendirme sicaklığ $1\left(105.2 \mathrm{C}^{\circ}\right)$

Şekil 9. P1 ve P2 doğrultularında alınan sıcaklık dağılımının karşılaştırılmalı incelenmesi
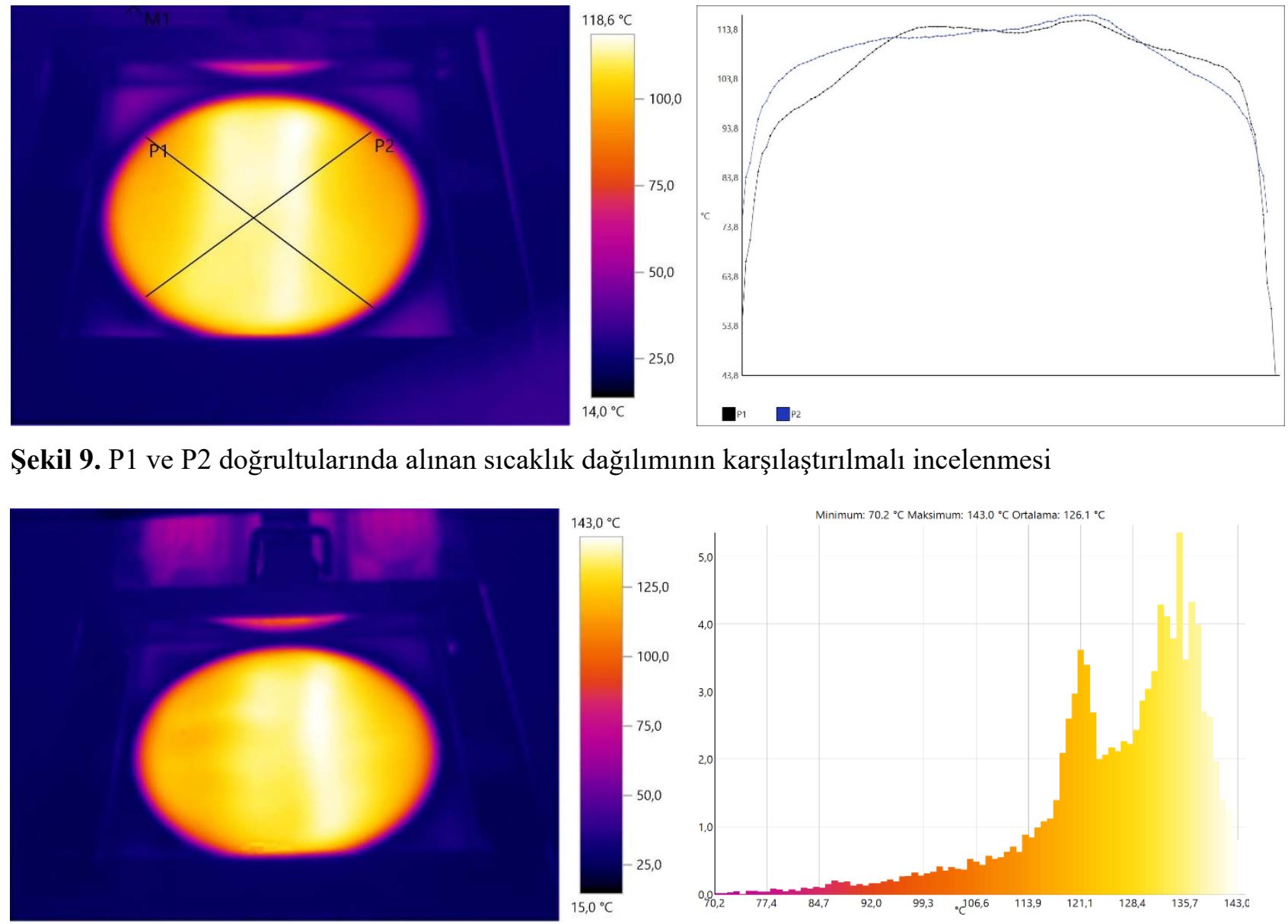

Şekil 10. 60 saniye 1sıtma süresinde PVC film üzerindeki sıcaklık dağılımı ve ortalama 1sıl şekillendirme sicaklığ $1\left(126.1 \mathrm{C}^{\circ}\right)$ 

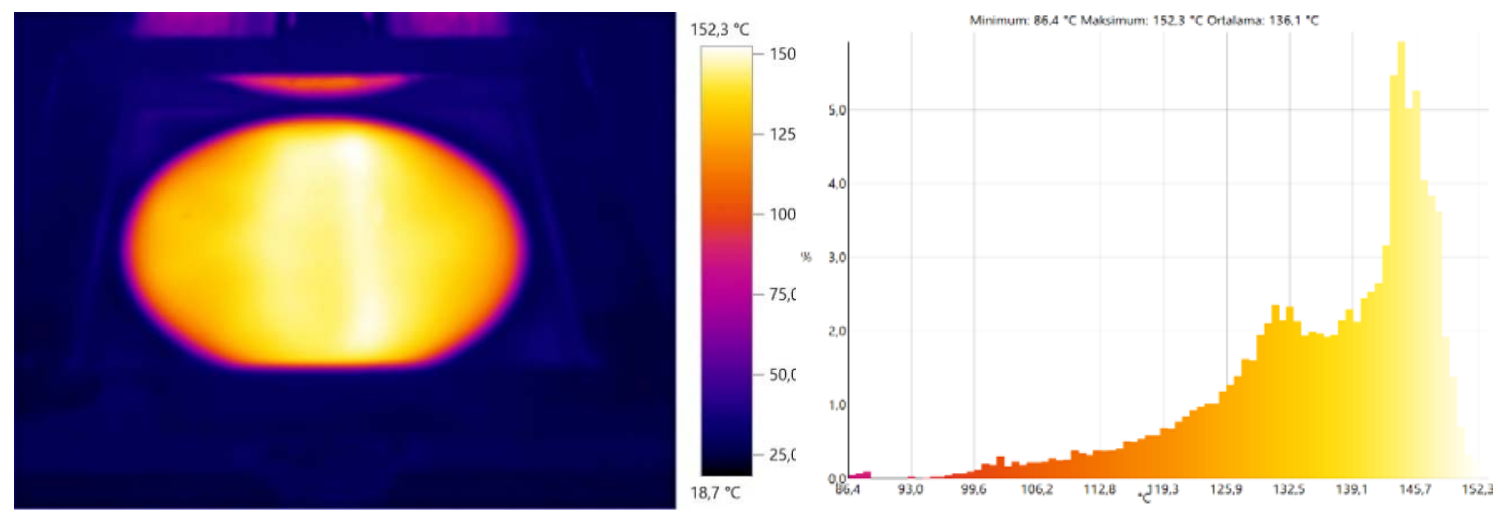

Şekil 11. 75 saniye 1sıtma süresinde PVC film üzerindeki sıcaklık dağılımı ve ortalama 1sıl şekillendirme sicaklığ $1\left(136.1 \mathrm{C}^{\circ}\right)$
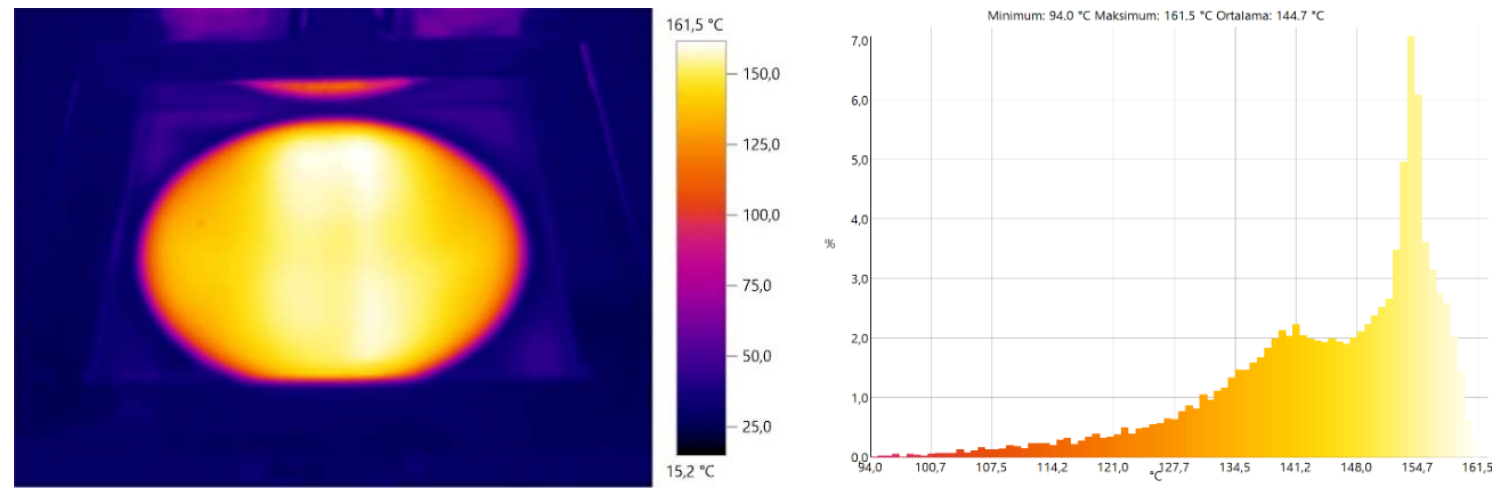

Şekil 12. 90 saniye 1 sıtma süresinde PVC film üzerindeki sıcaklık dağılımı ve ortalama ısıl şekillendirme sicaklığ $1\left(144.7 \mathrm{C}^{\circ}\right)$
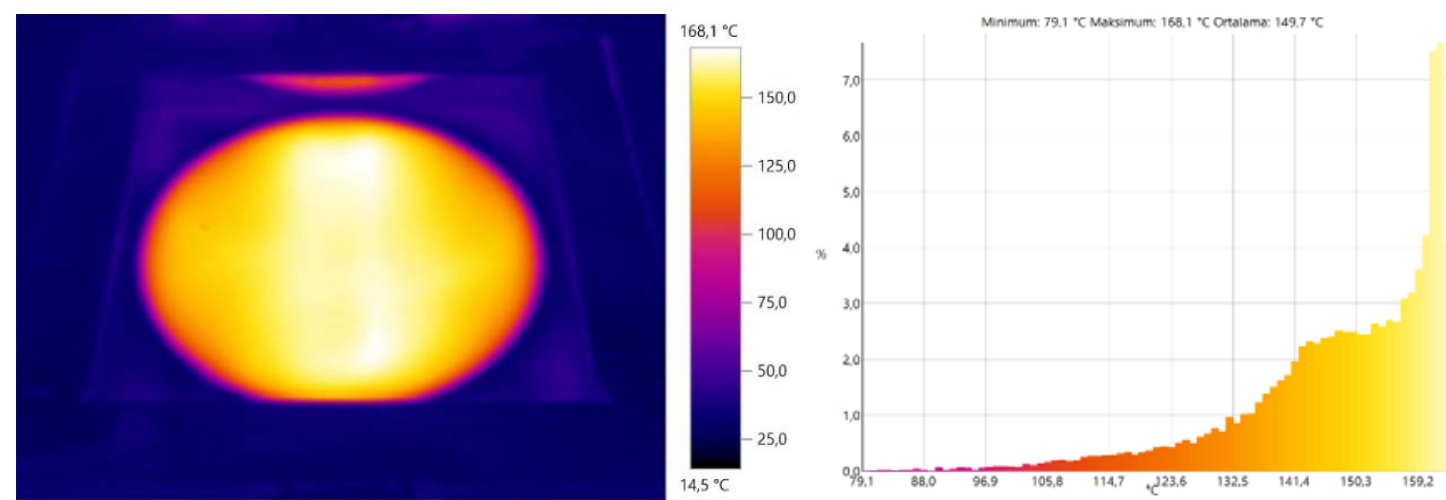

Şekil 13. 105 saniye 1sıtma süresinde PVC film üzerindeki sıcaklık dağılımı ve ortalama 1sıl şekillendirme sicaklı̆̆ $1\left(149.7 \mathrm{C}^{\circ}\right)$
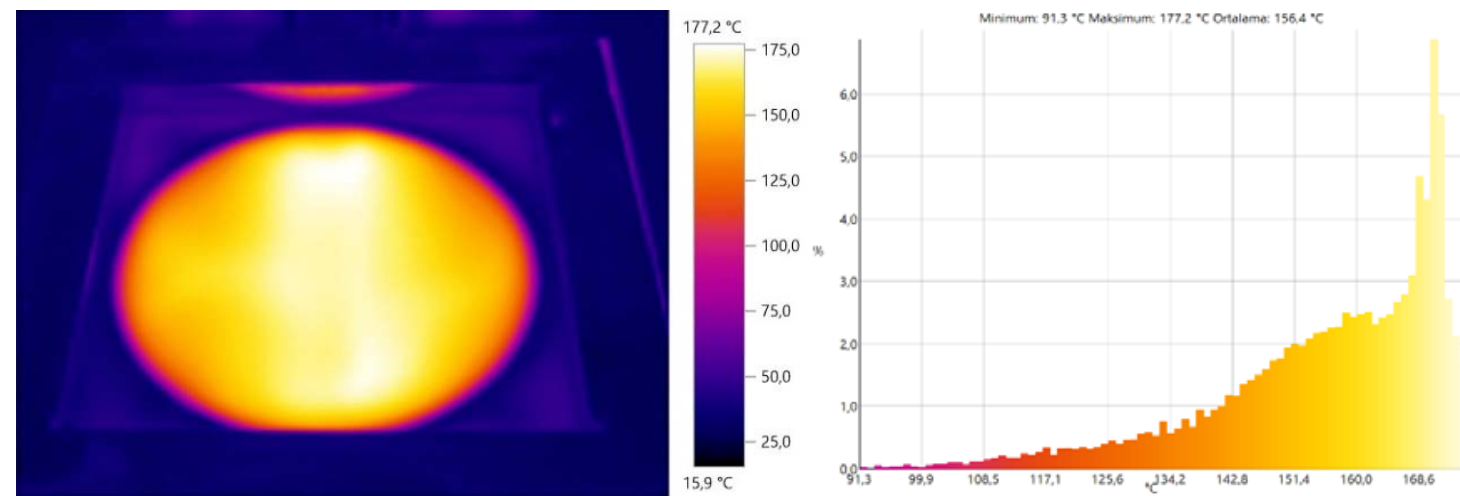

Şekil 14. 120 saniye 1sıtma süresinde PVC film üzerindeki sıcaklık dağılımı ve ortalama 1sı1 şekillendirme sicaklı̆̆ $1\left(156.4 \mathrm{C}^{\circ}\right)$ 
Termal görüntüler üzerinde ilk konumuna geri itilen 1sitıciların termal yansimaları da bulunduğundan ortalama sicaklık dağılımı alınırken filmin yüksek sıcaklıktaki, deforme olan elips şekilli alanı seçilmiştir. Termal görüntüler belirli bir açıyla alınabilmiştir. Laboratuvar tipi 1sıl şekillendirme ünitesinin boyutları, 1sıtılmış filmin termal görüntüsünün tam üstten alınmasını engellemiştir. Termal kameranın odak uzaklığının diși kalıbın üstündeki mesafeden daha fazla olması da yine termal görüntülerin belirli bir açıyla alınmasına neden olmuştur. Şekil 9'da, alınan farklı iki doğrultuda (P1, P2) sıcaklık dağılımının birbirinden farklı olduğu da gözlenmektedir. $\mathrm{Bu}$ unsur, kalınlık dağılımının farklı olmasına yol açan etkenlerden biridir. Özellikle sicaklığın, 1sıttılmış filmin alüminyum kalıp yüzeyine temas eden kısımlarında daha düşük olduğu buna karşın filmin kalıp yüzeyine temas etmeyen dairesel kısmında görece daha yüksek olduğu tespit edilmiştir. Ancak yine 1sitıcilara paralel yönde sicaklığın, 1sitıcilara dik yöndeki dağılımından farklı olduğu da gözle muayene edilebilmektedir. Şekil 15 ve 16, deneysel çalışmada elde edilen kalınlık dağılımlarını vermektedir. Şekil 15, erkek kalıbın dişi kalıp içerisindeki dalma derinliği $35 \mathrm{~mm}$ seçilerek ve erkek kalıp çapı değiştirilerek 1sıl şekillendirilen numunelerin kalınlık dağılımını karşılaştırmalı olarak vermektedir. Şekil 16 ise erkek kalıp çapı 40 mm seçilerek ve erkek kalıbın dişi kalıp içerisindeki dalma derinliği değiştirilerek ${ }^{\text {ssıl }}$ şekillendirilen numunelerin kalınlık dağılımını karşılaştırmalı olarak vermektedir. Şekil 15 ve 16 'da "Dişi kalıp" olarak verilen seri; erkek kalıp kullanılmadan 1s1l şekillendirilen numunelerin kalınlık dağılımını verdiği için bu şekilde adlandırılmıştır.

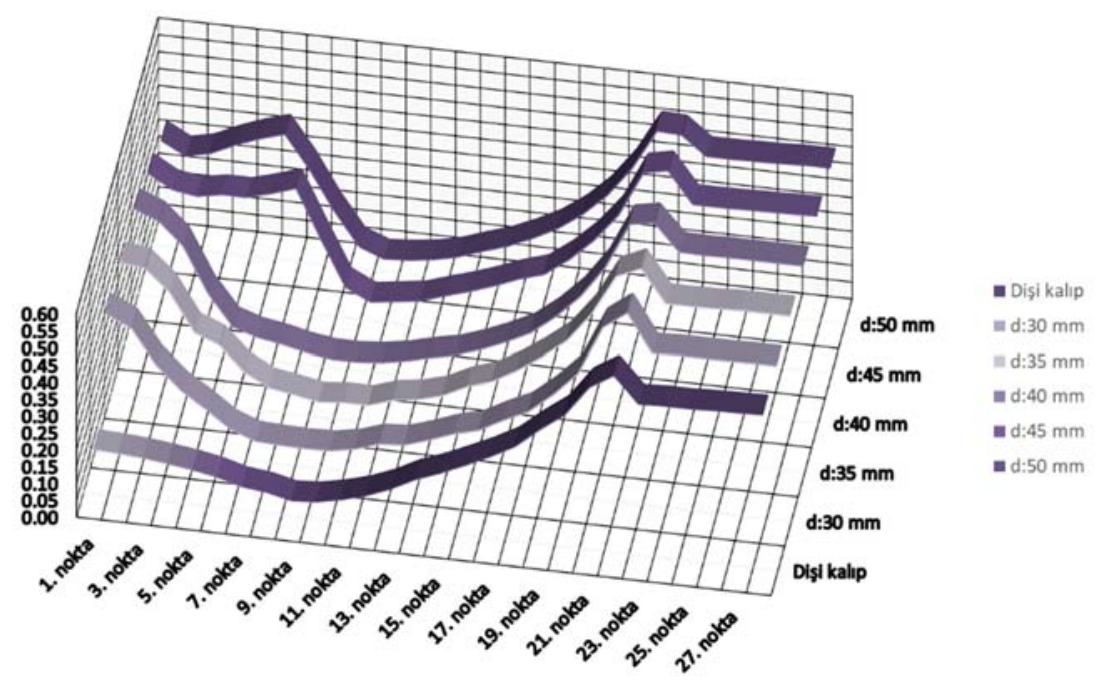

Şekil 15. Erkek kalıp çapının arttırılması ile 1sıl şekillendirilen numunelerin karşılaştırılmalı kalınlık dağılımları

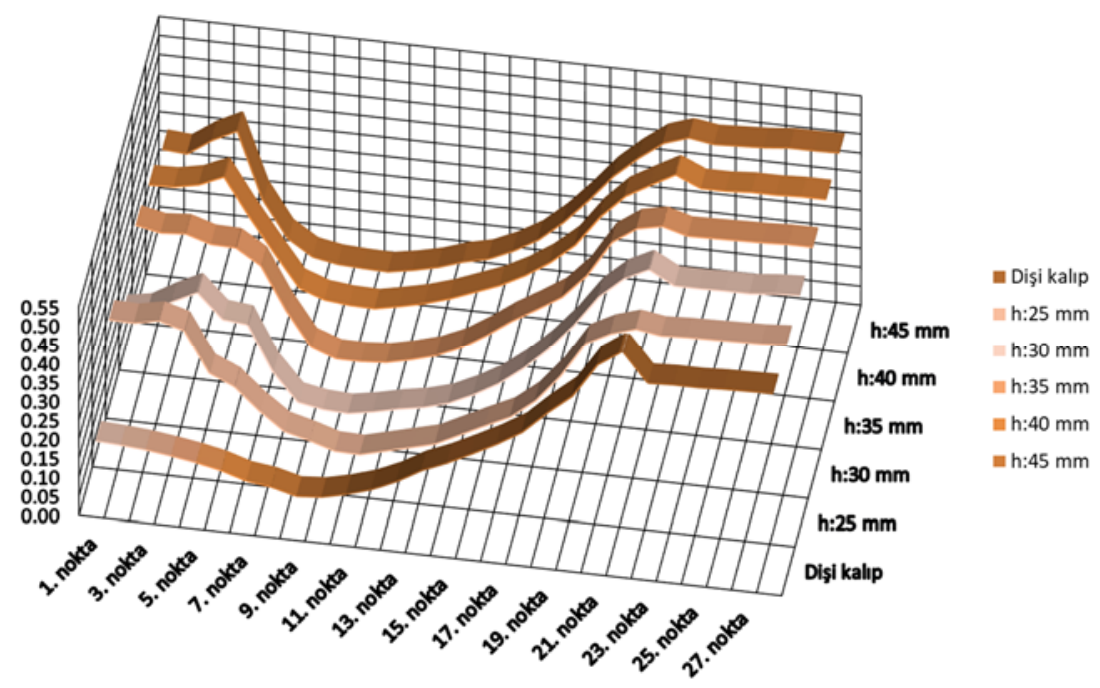

Şekil 16. Erkek kalıp dalma derinliğinin arttırılması ile 1sıl şekillendirilen numunelerin karşılaştırılmalı kalınlık dağılımları 
Şekil 7, Şekil 10, Şekil 11, Şekil 12, Şekil 13 ve Şekil 14'te 1sıl şekillendirme öncesi PVC film malzemenin sıcaklık dağılımı verilmektedir. Isıtma süresinin artışı PVC film malzemenin 1s1l şekillendirme sıcaklığını da artırmıştır. Isıl şekillendirme sıcaklıkları 30 saniye için $105.2 \mathrm{C}^{\circ}$, $60 \mathrm{~s}$ için $126.1 \mathrm{C}^{\circ}, 75 \mathrm{~s}$ için $136.1 \mathrm{C}^{\circ}, 90 \mathrm{~s}$ için 144.7 $\mathrm{C}^{\circ}, 105 \mathrm{~s}$ için $149.7 \mathrm{C}^{\circ}, 120 \mathrm{~s}$ için $156.4 \mathrm{C}^{\circ}$ olarak ölçülmüştür. PVC film malzeme yaklaşık $50 \mathrm{C}^{0}$ 'lik bir sıcaklık farkıyla isıl şekillendirilebilmiştir. Isı1 şekillendirme sıcaklığı; artan erkek kalıp çapıyla artış göstermiştir. Erkek kalıbın kullanılması, malzemedeki 1sıl şekillendirme sıcaklığını artırmıştır. Artan kalıp çapı ve dalma derinliği de malzemenin 1sıl şekillendirme sicaklığını artırmıştır. Bunun nedeni, oda sıcaklığındaki çelik erkek kalıbın sıcak PVC film malzemeye temas ettiğinde film sıcaklığını düşürerek hızlı soğumaya yol açmasıdır. Çelik 1sıyı iyi ilettiği için PVC ile temasta olduğu bölgelerde soğuma ve katılaşma hızla gerçekleşir ve bu bölgelerde şekil değiştirme meydana gelememektedir. Erkek kalıbın çapının artması 1sıtılmış PVC film malzeme ile temas yüzeyinin arttığı anlamına gelir. Bu yüzden erkek kalıp çap1 arttıkça 1sıtma süresi artırılmış ve başarılı bir 1sıl şekillendirme operasyonu için gerekli minimum sıcaklık değeri bulunmaya çalışılmıştır. Aynı eğilim artan erkek kalıp dalma derinliği için de söylenebilir. Artan dalma derinliği, oda sıcaklığındaki çelik kalıbın, ssıtılmış PVC film ile daha uzun süre temas etmesi anlamına gelir. $\mathrm{Bu}$ nedenle artan derinlik ile 1sıtma süresi artırılır ve başarılı bir 1sıl şekillendirme için gerekli asgari sicaklık değeri bulunmaya çalışılmıştır. Ancak en yüksek dalma derinliği $45 \mathrm{~mm}$ ve en büyük çap değeri $50 \mathrm{~mm}$ için 1 sıl şekillendirme sicaklığı, erkek kalıbın kullanılmadığı duruma göre neredeyse $50 \mathrm{C}^{\circ}$ lik artış göstermiştir. Elde edilen sonuçlar, Moustafa vd. (2015); Wang ve Nied (1999)'in elde ettiği sonuçlarla benzerdir. Kalıp malzemesinin iletkenliğinin yüksek olması ve 1sıtılmış polimer levhanın her noktasında eş sıcaklık verilerine sahip olması daha düzgün bir kalınlık dağılımına imkan tanımaktadır. Bu çalışmada ise, erkek kalıp malzemesinin iletkenliği yüksek bir malzeme olan çelik seçilmesi daha iyi bir kalınlık dağılımını desteklemekte, ancak 1sıtılmış termoplastik filmin sıcaklık dağılımının farklı olması kalınlık değişimini olumsuz yönde etkilemektedir. Sekil 17'de, $156.4 \quad \mathrm{C}^{\circ}$ 'de 1 s1l şekillendirilen numunelerde özellikle numune tabanının yüzeyinde meydana gelen değişimler, farklı büyütme oranlarıyla (10x, 20x) verilmiştir.

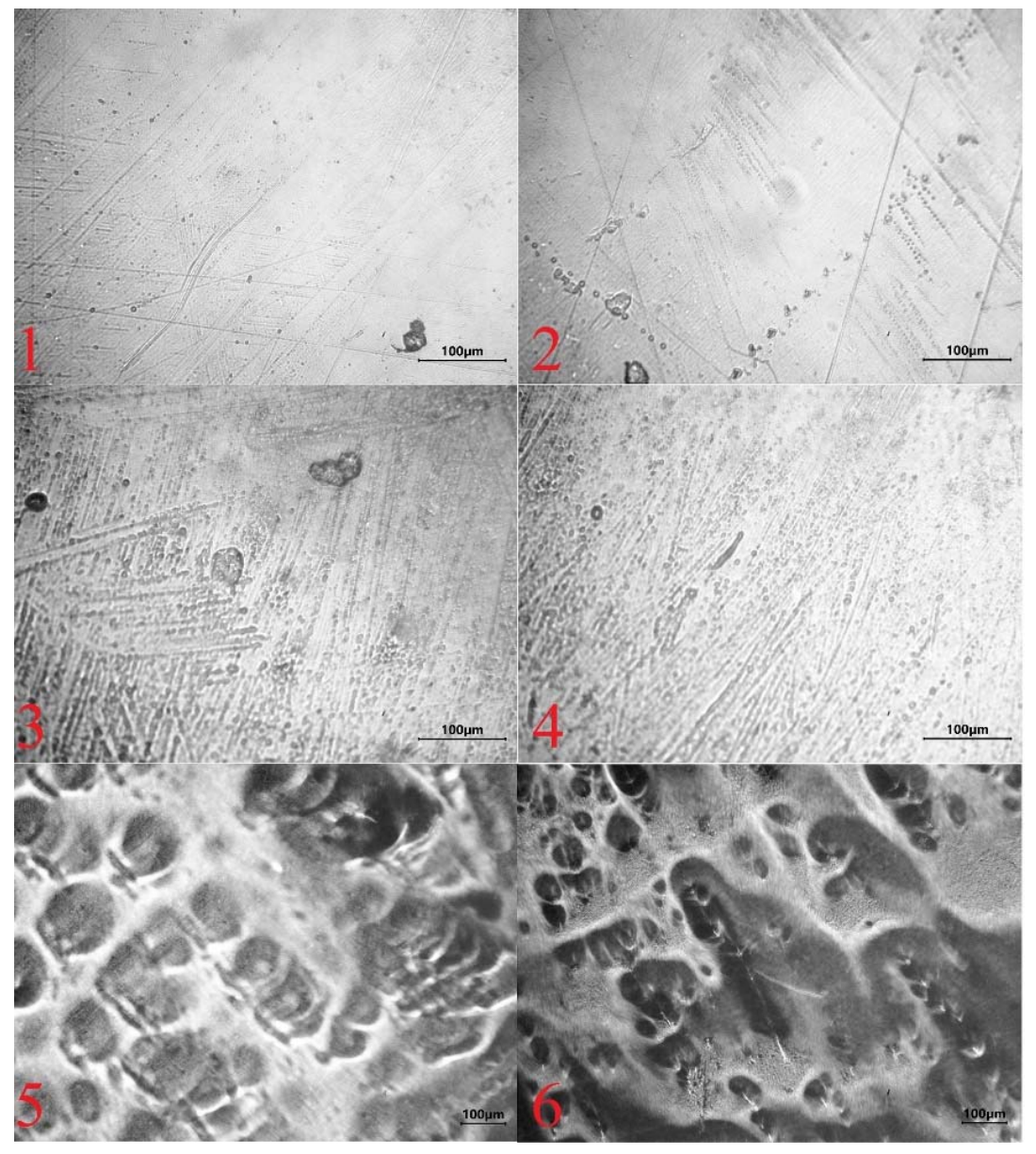

Şekil 17. 1-2. Isıl şekillendirme öncesi filmin yüzey görüntüleri (20x), 3-4. Sadece dişi kalıp ile 1sıl şekillendirilen numunenin tabanından alınan görüntüler (20x), 5-6. $50 \mathrm{~mm}$ çaplı erkek kalıp kullanılarak 1s1 şekillendirilen numunenin tabanına erkek kalıbın temas ettiği farklı iki noktadan alınan görüntüler (10x). 
Şekil 18 ve 19'da, erkek kalıbın çapındaki artış özellikle numunelerin merkezindeki kalınlık değerlerini artırmıştır. Özellikle 8. noktaya kadar olan bölümde, erkek kalıp kullanılarak elde edilen 1sıl şekillendirilmiş numunelerin kalınlık değerleri, erkek kalıp kullanılmadan 1sıl şekillendirilenlerden daha yüksektir. Buda numunenin taban merkezindeki (1. nokta) ve tabanındaki (1-10. noktalar) kalınlığın erkek kalıp kullanımıyla arttığını doğrulamaktadır. Değişken dalma derinliği ve değişken çap uygulaması dikkate alındığında her iki senaryo içinde minimum kalınlık oluşumu 10. noktada gerçekleşmiştir. Ek olarak erkek kalıp kullanılarak ısıl şekillendirilen numunelerin neredeyse tümünde ölçülen en düşük kalınlık değeri, erkek kalıp kullanılmadan 1sıl şekillendirilen numunelerinkinden daha düşük olmuştur. Yine erkek kalıp kullanımı her iki senaryo içinde numunelerin yan duvar kalınlıklarını dişi kalıpla 1 sıl şekillendirilen numunelerinkine göre azaltmıştır (10-22. noktalar). Numune üst kenarında (23-28. noktalar) ise kalınlık dağılımı erkek kalıp kullanımından
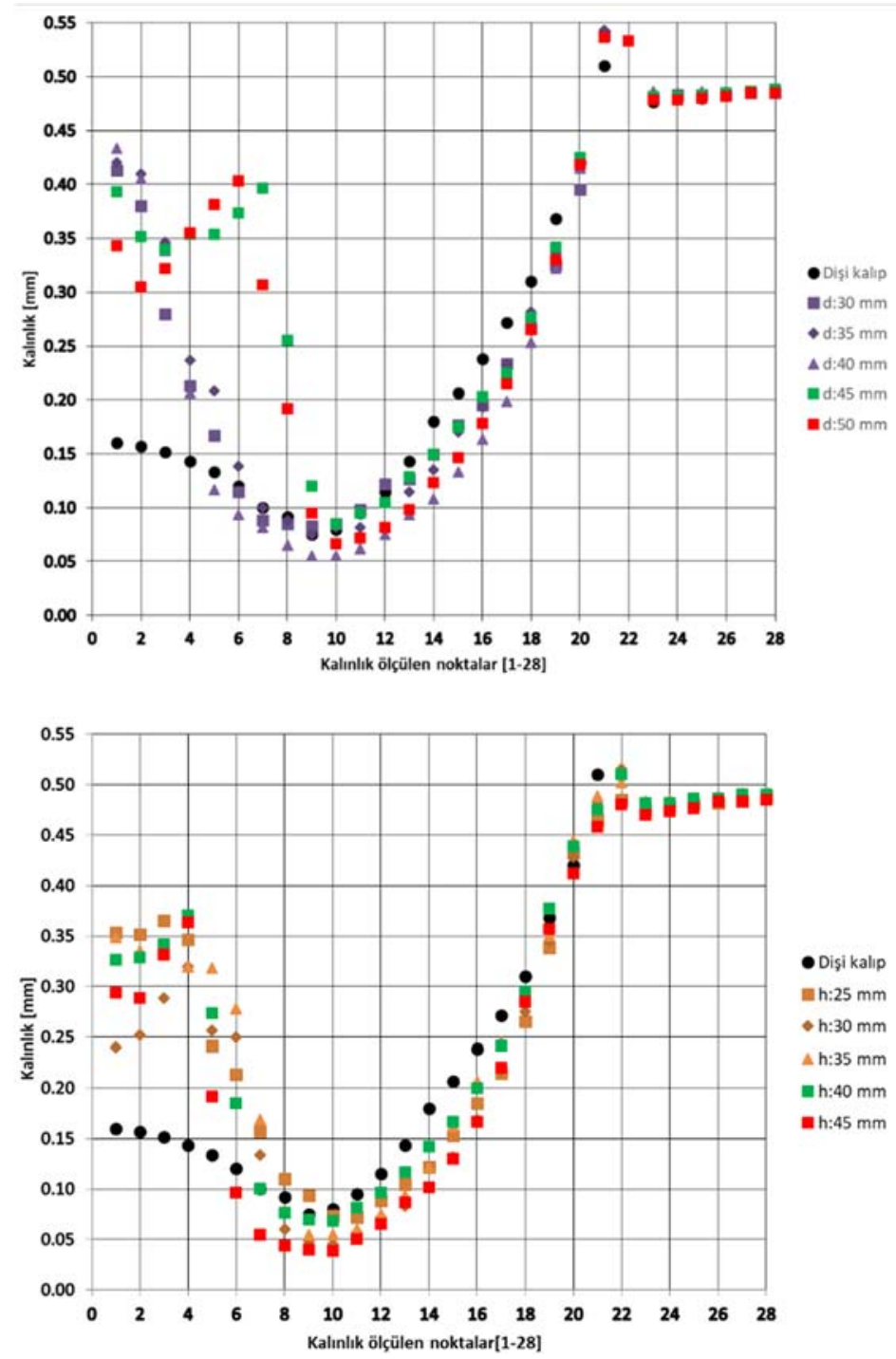

etkilenmemiştir. Her iki senaryo için 21 ve 22. noktalarda kalınlık değerlerinde ani artışlar olduğu gözlenmiştir. Bunun nedeni bu bölgedeki yarıçap üzerinde kısmi katlanmaların oluşmasıdır. Ek olarak, özellikle $\varnothing 45$ ve $\varnothing 50 \mathrm{~mm}$ ölçüsündeki erkek kalıp ile 1sıl şekillendirilen numunelerde 4. ve 8 . noktalar arasında kalınlık azalması beklenirken artış olmuştur. Bunun nedeni ise daha önce de bahsedilen yüksek ssıl şekillendirme sıcaklığ 1 nedeniyle 1sıtılan PVC filmin aşırı sarkması ve vakum etkisinde hızla şekil değiştirerek katlanmanın oluşmasıdır. Bu etki, değişken dalma derinliği için yapılan isıl şekillendirilmiş numunelerde görülmemektedir. Elde edilen veriler, Morales vd. (2014), ve Chen vd. (2008)'in sonuçlarıyla karşılaştırıldığında kalınlık dağılımını etkileyen unsurların aynı değişimi gösterdiği saptanmıştır. Özellikle kalıp malzemesi, boyutları ve dalma derinliğinin 1s1 şekillendirilen ürünün yan duvar kalınlıklarını değiştirdiği belirtilmiştir ve deneysel çalışmayı destekler niteliktedir.
Şekil 18. Erkek kalıp çapının arttırılması ile 1 sıl şekillendirilen konik numunelerin karşılaştırılmalı kalınlık dağılımları
Şekil 19. Erkek kalıp dalma derinliğinin arttırılması ile 1sıl şekillendirilen konik numunelerin karşılaştırılmalı kalınlık dağılımları 


\section{Tartışma ve Sonuçlar}

PVC'nin 1sıl şekillendirilmesinde, erkek kalıp kullanımının, numunelerin özellikle taban merkezindeki ve yan duvar kalınlığını değiştirdiği belirlenmiştir. Ancak numunelerde oluşan en düşük kalınlık değerinde kayda değer bir değişim görülmemiştir. Artan erkek kalıp çapı ve dalma derinliği ile numunelerin 1sıl şekillendirme sıcaklığı da artmıştır. Yaklaşık $50 \mathrm{C}^{\circ}$ lik bir sicaklı fark1 ile PVC film malzeme 1sıl şekillendirilebilmiştir. Bunu mümkün kılan ise PVC'nin zincir dizilişine göre amorf yapıda bir mühendislik termoplastiği olmasıdır. Kalınlık dağılımını en çok etkileyen unsurlardan biri de; oda sıcaklığındaki çelik erkek kalıbın sıcak film malzemeye temas ettiğinde ani soğumaya ve katılaşmaya neden olmasıdır. Isıl şekillendirme öncesi film sıcaklık dağılımının da yer yer farklılık göstermesi kalınlık dağılımına etki eden unsurlardandır. Elde edilen termal görüntüler, 1sıtılmış film üzerindeki sıcaklık dağılımının her noktada farklı olabileceğini ortaya koymuştur. Isitılan PVC film üzerinde birbirine dik doğrultularda yapılan sicaklık dağılımı karşılaştırmasında bazı noktalarda $20 \mathrm{C}^{\circ}$ 'yi bulan sıcaklık farkları tespit edilmiştir. Buna ek olarak erkek kalıp kullanımı 1sıl şekillendirilen numunenin yüzeyinde değişimlere yol açmıştır. Özellikle çelik malzemeden imal edilen erkek kalıbın 1sıl şekillendirilen numuneye temas ettiğ $i$ bölgelerde mikron mertebesinde boşlukların oluştuğu tespit edilmiştir. PVC malzeme, amorf yapıda bir termoplastik olmasindan dolayı gida ambalajlama başta olmak üzere kaplanabilmekte ve farklı sektörlerde kullanım alanı bulabilmektedir. Ek olarak, amorf yapida olan diğer 1sıl şekillendirilebilen Polistiren (PS), Akrilonitril Bütadien Stiren (ABS), Polimetil Metakrilat (PMMA) ve Polikarbonat (PC) gibi farklı özellikleri olan termoplastikler de uygun 1sıl şekillendirme sıcaklığında benzer deformasyon özellikleri gösterir. Ancak yarı kristalin yapıdaki Polipropilen (PP) ve Polietilen (PE) gibi 1s1l şekillendirme sıcaklık aralığı oldukça dar olan plastikler, PVC ile aynı deformasyon davranışını göstermez.

\section{Kaynaklar}

Barry, C.M.F., Baker, A-M. ve Mead, J.L., 2006. Introduction to Polymers and Plastics, in: Harper, C.A. (Eds.), Handbook of Plastics Technologies. McGraw-Hill Companies, New York.

Crawford, R.J., 1998. Plastic Engineering: Oxford, Butterworth-Heinemann, 306-309 pp.
Chen, S-C., Huang, S-T., Lin, M-C. ve Chien, R-D., 2008. Study on the Thermoforming of PC Films Used for In-Mold Decoration. International Communications in Heat and Mass Transfer, 35, 967-973.

Hosseini, H., Berdyshev, B.V. ve Mehrabani-Zeinabad, A., 2006. A Solution for Warpage in Polymeric Products by Plug-Assisted Thermoforming. European Polymer Journal, 42, 1588-1600.

Morales, R.A., Candal, M.V., Santana, O.O., Gordillo, A. ve Salazar, R., 2014. Effect of the Thermoforming Process Variables on the Sheet Friction Coefficient. Materials and Design, 53, 1097-1103.

Moustafa, M., Dotchev, K., Wells, S., Bennett, N. ve Cawkell, J., 2015. Investigation of Thermoforming Tool Design and Pocket Quality. Journal of Thermal Engineering, 1, 670-676.

O’Connor, C.P.J., Martin, P.J., Sweeney, J., Menary, G., Caton-Rose, P. ve Spencer, P.E., 2013. Simulation of the Plug-Assisted Thermoforming of Polypropylene Using a Large Strain Thermally Coupled Constituve Model. Journal of Materials Processing Technology, 213, 18361843.

Penix, J.A., 1991. Thermoforming of Plastic Film and Sheet, in: Berins, M.L. (Eds.), SPI Plastics Engineering Handbook of the Society of the Plastics Industry, Inc. Van Nostrand, New York, p. 383 .

Pribble, W.I., 2013. Introduction to Plastics Processing, in: DuBois, J.H., Pribble, W.I. (Eds.), Plastic Mold Engineering Handbook. Springer-Verlag, New York.

Rosato, D. ve Rosato, D., 2004. Reinforced Plastics Handbook: Amsterdam, Elsevier, 1-18 pp.

Rosato, D.V., Rosato, M.G. ve Schott, N.R., 2001. Plastics Institute of America Plastics Engineering, Manufacturing \& Data Handbook: New York, Springer-Verlag.

Schwarzman, P. ve Illig, A., 2018. Thermoforming A Practical Guide: Munich, Hanser.

Throne, J.L., 1996. Technology of Thermoforming: Munich, Hanser.

Wang, C-H. ve Nied, H.F., 1999. Temperature Optimization for Improved Thickness Control in Thermoforming. Journal of Materials Processing and Manufacturing Science, 8, 113-126. 